\title{
The strategic paradox of autonomous weapons
}

\section{ZIPAR Policy Brief}

February 2018

Marko Kovic 


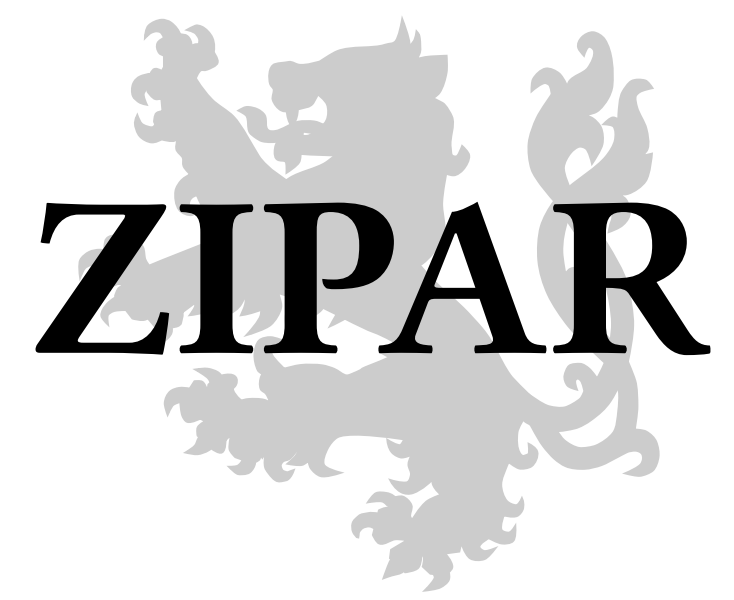

\section{About ZIPAR}

The Zurich Institute of Public Affairs Research is devoted to identifying and addressing the major challenges for humankind in the short-term, in the mediumterm, and in the long-term future. ZIPAR is an independent nonprofit think tank based in Zurich, Switzerland.

\section{Recommended citation}

Marko Kovic (2018): The strategic paradox of autonomous weapons systems. ZIPAR Policy Brief. Zurich, Switzerland.

\section{Copyright}

This document is licensed under a Creative Commons Attribution-NonCommercialNoDerivatives 4.0 International license. You can freely distribute this document and reference it in other works. For any questions about copyright, feel free to contact the author (marko.kovic@zipar.org). 


\begin{abstract}
Progress in artificial intelligence makes the technology increasingly relevant to military applications. In particular, autonomous weapons could be of great military use: Autonomous weapons could achieve goals more effectively and more efficiently than humans or human-operated weapons. In this policy brief, the potential impact of implementing autonomous weapons on the behavior and decision-making of the military is discussed. The most probable positive impact, greater adherence to humanitarian law on the battlefield, is outweighed by the most probable negative impact, a disruption of the military chain of command and the security risks that follow from that disruption. This creates a strategic paradox: Even though autonomous weapons could help the military achieve goals more effectively and more efficiently, autonomous weapons would strategically undermine the military by disrupting the chain of command and by creating a great security risk.
\end{abstract}




\section{Contents}

\begin{tabular}{llr}
\hline Introduction: Peace and war & 5 \\
\hline
\end{tabular}

1.1 How viable is the technology? . . . . . . . . . . . . 5

\begin{tabular}{|lll}
2 & Potential outcomes of introducing autonomous weapons
\end{tabular}

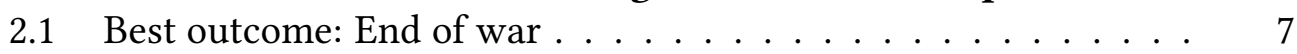

2.2 Good outcome: Moral improvements on the battlefield . . . . . 8

2.3 OK outcome: Mutually assured AI destruction (MAAID) . . . . 9

2.4 Bad outcome: Lowering the threshold for engaging in war . . . 10

2.5 Worst outcome: Disrupting the chain of command . . . . . . . 11

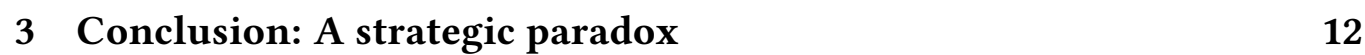

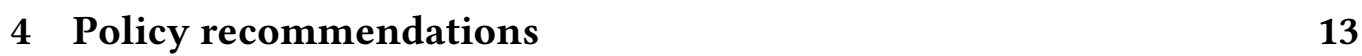

$4.1 \quad$ Military level: Abstaining from autonomous weapons . . . . . . 13

$4.2 \quad$ International level: Codification of an ordo belli . . . . . . . . . 13 


\section{Introduction: Peace and war}

We live in increasingly peaceful times. On average, fewer humans are experiencing violence today than ever before [1], and there are fewer and less violent armed conflicts between states than ever before [2, 3]. At the same time, warfare capabilities are growing; perhaps not in the sense of the absolute volume of firepower, but certainly in terms of the technological sophisticiation of warfare machinery. Technological progress of military machinery, including weaponry, is not surprising. After all, more advanced weaponry can, all else being equal, provide both specific tactical advantages on the battlefield and more general strategic advantages in military policy as well as in war.

Artificial intelligence is an umbrella term for software that is able to achieve goals in an «intelligent» manner by incorporating environmental stimuli that are not part of a pre-programmed routine. In a very general sense, artificial intelligence can have similar benefits in military applications as it does in civilian contexts: Goals can be achieved more efficiently, more effectively, or both. Artificial intelligence in military applications, however, is more controversial than in civilian applications, because the goals that are being pursued in the military context are quite different from goals that are being pursued in civilian contexts. Creating cars that drive autonomously, for example, is very different from creating weapons that autonomously destroy targets and incapacitate or kill humans. Consequently, there is an ongoing and intense debate on the legal and moral nature of autonomous weapons [4].

The formal legal status of autonomous weapons (whether and in which circumstances they are legal) follows from their moral status. But what is the moral status of autonomous weapons? Should we want autonomous weapons to exist and to be implemented by military forces? The idea of autonomous weapons creates some understandable intuitive moral concerns. However, just because autonomous weapons might not feel quite right does not mean that they are undesirable from a more rational point of view (and vice versa). In this policy brief, autonomous weapons are discussed not in terms of a priori (deontological) moral implications, but instead in terms of the potential impact autonomous weapons might have if they were implemented by military forces.

\subsection{How viable is the technology?}

Weapons that are partially or fully automated exist today, but truly autonomous weapons do not. The current debate about autonomous weapons is therefore not a debate about technology that could immediately be implemented, but rather a debate about a potential future category of weapons technology [5].

Autonomous weapons are weapons that are able to achieve the goals they 
are given by interacting with their environment in ways that go beyond simple stimulus-response automation. In essence, autonomous weapons have to have the complex decision-making capabilities that humans have, be it as soldiers on the ground or as commanders higher in the military decision-making chain. Achieving the necessary level of technological sophistication might simply be a matter of incremental technological progress. But it is also possible that autonomous weapons require a categorical technological jump to so-called artificial general intelligence [6]. Artificial general intelligence is artificial intelligence that is able to operate in domains for which it was neither designed nor trained. By doing so, artificial general intelligence would be intelligent in much the same way we humans are intelligent. In order to achieve our goals, we are able to operate across all kinds of domains, not just withing the very narrow domain in which the goal we are trying to achieve is located.

It is not clear whether autonomous weapons really require artificial general intelligence, and it is not clear when, if ever, artificial general intelligence will emerge [7]. For the purpose of this policy brief, it is simply assumed that truly autonomous weapons in the sense of sufficiently intelligent weapons for battlefield deployment will become a reality, either through incremental advantages in «regular» AI technology or through artificial general intelligence.

\section{Potential outcomes of introducing autonomous weapons}

The impact autonomous weapons could have on humankind is very difficult to predict. There are many aspects of society that could, in one way or another, be affected by the introduction of autonomous weapons. The focus of this policy brief is on a «big picture», macro-level perspective. This means that this policy brief does not address how specific military forces might make use of specific forms of autonomous weapons in specific situations. Instead, the question of interest here is how autonomous weapons technology might impact the military in a general and principled way: If we assume countries' military forces to be rational actors, how might autonomous weapons affect their behavior, directly or indirectly?

Some potential ways in which autonomous weapons might influence the behavior of military forces are discussed in the following sections. These potential outcomes are not a complete list, but they represent some plausible outcomes with non-trivial probabilities on a spectrum from best to worst. The spectrum represents an evaluation of the potential outcomes from the perspective of a democratic society. The rational goals of a democratic society with regards to its 
military's behavior are effectiveness, efficiency, adherence to moral principles, and, all else being equal, as little armed conflict as possible.

\subsection{Best outcome: End of war}

War is a continuation of politics, as the famous saying by von Clausewitz goes [8]. In the past century, however, the status of war has changed. In the Charter of the United Nations of 1945, international war was declared illegitimate in principle, except in cases of self-defence in which a country defends against an aggressor country [9, 10]. This is the basis of modern-day jus ad bellum, the criteria that specify when war is legitimate and when it is not. War still exists today, and military conflicts even between great powers are not as improbable as we might want to believe [11]. There is at least tacit consensus that preventing and avoiding war is a high global priority. Autonomous weapons systems could help in this regard: It is possible that autonomous weapons would lead to the end of war altogether.

Warfare is enormously costly, both in terms of financial expenditure as well as in terms of human lives. War means that humans risk their lives in order to fight and kill enemy combatants. War results in suffering and death on the battlefield, but it also does more subtle mental and cognitive damage to soldiers and other kinds of military personnel [12], and war causes great suffering for civilians who are directly or indirectly affected by war. This could drastically change with autonomous weapons.

Imagine a war between two countries in which all fighting is done entirely via autonomous weapons. On the battlefield, autonomous weapons are pitted against other autonomous weapons. No humans make decisions on the battlefield, and no human combatants are harmed or killed on the battlefield. Such a war is not a traditional war, but rather something like a war game: A violent conflict with real-world political consequences, but without the immediate human sacrifice associated with regular war. Over time, the prospect of war as war game might change the perception of the strategic role of war in and of itself. If war transforms from an act of actively killing human adversaries into an act of tactical and strategic combat engagement of warfare machinery, the utility of warring might diminish. If two or more parties are engaged in a war game with autonomous weapons, the conflict at hand might become very protracted. Autonomous weapons are both more expendable and more fungible than soldiers. Even large initial differences in warfare capability between the warring parties might vanish soon after a conflict begins. Even small countries might be able to swiftly ramp up the procurement of autonomous weaons, be it through their own production, be it through international weapons manufacturers, or be it through 
support by allied countries 1

Protracted military conflicts are against the strategic interests of any military force. The prospect of war as war game might thus diminish the utility of war. Ultimately, this diminishing utility of war might end war altogether, since other means of pursuing interests (diplomacy, bilateral and international cooperation, soft power) might prove to be more effective. While the adoption of autonomous weapons might bring about the end of war in this manner, the probability of this outcome is very low. In order for this outcome to become reality, a number of conditions have to be met, such as the universal adoption of autonomous weapons as the only means of conducting war. It is highly improbable that such a complete shift towards autonomous weapons will happen anytime soon. Overall, I believe that the probability for this outcome is somewhere around 0.01 to 0.05 .

\subsection{Good outcome: Moral improvements on the battlefield}

War has always created suffering. Over the centuries, however, the morality of warfare has improved. For example, spoils of war for the victors, including raping women and pillaging, used to be common military practice. Today, there are jus in bello rules that define morally acceptable and morally unacceptable behavior during warfare. These rules are the rules that comprise international humanitarian law, both as formal treaties and as customary law [13].

The broad strokes of humanitarian law, such as the Geneva Conventions, are almost universally accepted. However, humans make errors, and we can be irrational, emotional, sadistic, psychopathic, and so forth. Morally acceptable behavior in war is difficult to monitor and almost impossible to enforce. Autonomous weapons could make a significant positive impact in this area: Since autonomous weapons achieve their goals with the help of artificial intelligence, that artificial intelligence can be designed in such a way that moral principles of humanitarian law are at the top of the autonomous weapons' utility function [14. 15, 16].

All the errors and biases that we humans are prone to do not exist in artificial intelligence (Unless we design the artificial intelligence in such a faulty way.). In addition, the rules of humanitarian law can be very explicitly and formally implemented in autonomous weapons, without the possibility that the autonomous weapon can override those rules. After all, artificial intelligence is simply a utility-maximizing apparatus that seeks to achieve the goals it is designed to achieve. This is a very simple point, but one that might run counter to a more intuitive understanding of morality in the context of artificial intelligence. We

\footnotetext{
${ }^{1}$ Countries are very cautious when it comes to actively participating in military conflicts with their own armed forces. Providing autonomous weapons to allies, on the other hand, would not amount to active participation in the conflict at hand.
} 
might feel that artificial intelligence is intrinsically «bad» or «evil» because it is only a machine, not a human. In reality, however, artificial intelligence is merely a tool that performs (some) tasks better than humans, precisely because it does not suffer from our human limitations. If our goal is to wage war in a morally acceptable manner, then artificial intelligence could help us do so better.

I believe that the probability for this outcome is very high, somewhere between 0.8 and 1.

\subsection{OK outcome: Mutually assured AI destruction (MAAID)}

One consequence of autonomous weapons could be that warfare capabilities might proliferate. In the past, a country's military capabilities have been, to a degree at least, a function of the country's size and wealth. With autonomous weapons, that might change, because autonomous weapons machinery could be relatively cheap and readily available. Artificial intelligence software is scalable: You do not need to create new software for each piece of weapons machinery. Artificial weapons machinery, in turn, could be cheap and mass produced. Whereas a single traditional bomber jet costs millions of US Dollars, small, unammed drones cost only a fraction of that. The difference in firepower could easily be compensated by greater numbers.

Autonomous weapons, therefore, might result in a greatly levelling arms race: Large military forces would remain large, but very small military forces might catch up significantly and rapidly. Rapid dissemination of military capability might not seem like a desirable development. It might, however, result in a stable equilibrium that reduces the overall probability of armed conflict: Mutually assured AI destruction, or MAAID. Mutually assured destruction, or MAD, is a game-theoretic concept that aims to explain why the Cold War between the United States and the Soviet Union remained cold [17, 18]. According to the MAD explanation or doctrine, knowing that one's adversary will respond by nuclear destruction if attacked with nuclear weapons creates an equilibrium through deterrence. No rational actor has anything to gain through a nuclear attack. MAAID might have a similarly deterring effect that creates a stable equilibrium: Since autonomous weapons capabilities are very similar even between large and small countries, it would be rational for all actors to assume that any potential adversary is able to match their own military capabilities. Such an assumption is rational because software scales regardless of country and military size. Even a tiny military force could defeat the greatest military force if its artificial intelligence was sophisticated enough.

MAAID seems like a somewhat plausible outcome, but a MAAID equilibrium is much less probable than a MAD equilibrium. Nuclear weapons have immediate catastrophic destructive consequences, whereas automated weapons do 
not, limiting their deterrence power. Furthermore, the damage that can be done with automated weapons requires more decisions and more complex decisions than launching strategic nuclear weapons. Launching a nuclear counterattack is a single decision that results in complete destruction, whereas a counterattack with automated weapons is a more complex, regular military operation. Unless automated weapons become so potent that a single decision can have similarly far-reaching catastrophic consequences as nuclear weapons, MAAID is unlikely. I believe the probability the MAAID outcome is low, somewhere between 0.05 and 0.15 .

\subsection{Bad outcome: Lowering the threshold for engaging in war}

Engaging in armed conflicts is a costly affair in several ways. There are immediate financial costs that armed conflicts incur, and there are political, social, and moral costs. For example, some people might not care much about the cost of armed conflict, but they might care about the human suffering their soldiers and civilians on the battleground might experience. Political decision-makers as well as the public are usually hesitant when it comes to engaging in armed conflict. The cost-benefit analysis of armed conflict might change with the introduction of autonomous weapons.

Deploying autonomous weapons would not be without costs. Creating, maintaining and deploying autonomous weapons requires financial resources, and armed conflict waged with autonomous weapons would still have political, social, and moral implications and consequences. However, some costs of autonomous weapons are almost certainly lower than costs of regular warfare. Primary among them is the question of loss of human life: Contrary to regular warfare, warfare through autonomous weapons could play out without putting any human soldiers directly in harm's way. If all conflict parties were to use autonomous weapons, this cost could be reduced further still. If the fighting is taking place predominantly or exclusively between autonomous weapons, then few to no human lives have to be lost. In addition, civilian victims and casualties might be avoided, perhaps altogether, if autonomous weapons outperform humans in adhering to humanitarian law.

Reducing the cost of warfare is, in principle, desirable, because lower costs means that military goals can be achieved with fewer resources. But there is a downside to reducing the cost of war: If armed conflict becomes less costly, that could be an incentive for engaging in armed conflict more often. Reducing the cost of war might, in other words, lower the threshold for engaging in war. Costs are not the only determinant of war, of course (goals are the primary determinant), 
but lower costs act as an incentivizing mechanism: If one has less to lose, then taking action might become more appealing, simply because the cost-benefit relationship has shifted in favor of the benefits. Overall, however, the thresholdlowering property of autonomous weapons is likely to be limited because the decreases in costs induced by autonomous weapons will probably remain limited. I believe that the probability for this outcome, therefore, is low, but not trivially low, somewhere between 0.1 and 0.2 .

\subsection{Worst outcome: Disrupting the chain of command (and creating new security risks)}

A core principle of military action is that there is a chain of command at all times. The military is a strictly hierarchical organization in which commands are given in a clear and unambiguous manner. This means that decision-making in the military is explicit and explicitly top down. Autonomous weapons disrupt this military chain of command to some degree because they make decisions that are neither controllable nor comprehensible or replicable after the fact.

On a tactical level, autonomous weapons simply try to achieve the goals they are given; they «follow orders», so to speak. In doing so, they might be much more efficient and effective than human soldiers. However, the decision-making process is categorically different with autonomous weapons. What makes autonomous weapons autonomous is precisely the fact that they make some decisions autonomously, without a prior command to do so. This means that autonomous weapons can be given goals and a general set of behavioral guidelines, but the very specific decisions autonomous weapons have to make on the battlefield are outside the military chain of command. One area in which autonomous decisionmaking by autonomous weapons is apparent is the problem of targeting [19]. In many, if not all military operations, potential targets have to be identified and classified as part of the tactics at hand as well as of the overall military strategy. As much targeting as possible is done beforehand, in order to, for example, engage in a battle with as good a plan as possible. However, it is practically impossible to pre-program an autonomous weapon with a complete list of targets and then field it, because identifying and classifying targets is an inherently dynamic and to some degree stochastic process that cannot be completely performed a priori. That is why truly autonomous weapons have to perform targeting autonomously, and then make decisions based on their autonomous targeting. Such decisions by autonomous weapons do not only disrupt the military chain of command during a mission. Even after a mission, the decisions made by autonomous weapons are only partially or not at all understandable and replicable [20]. This means that autonomous weapons disrupt the military chain of command during battle, and 
there is no clear path towards understanding autonomous weapons' decisions after the fact.

Disrupting the chain of command with autonomous weapons is not only a matter of military principle. When truly autonomous weapons are deployed and they make decisions autonomously, the military force that has deployed them has, effectively, not only given up command, but also control. More specifically: The moment an autonomous weapon is deployed, the military force that deployed it cannot know whether the autonomous weapon is acting based on its internal artificial intelligence, or based on interferences from the enemy forces or even some other third party. This means that autonomous weapons create an enormous security risk for the military: Hostile military forces and other kinds of adversaries have obvious incentives to tamper with one's autonomous weapons, and as soon as any single autonomous weapon is fielded, there is no way of knowing whether the weapon has, indeed, been tampered with or is being tampered with at that very moment.

Autonomous weapons have the potential of disrupting a core principle of the military, chain of command, and they potentially represent an enormous security risk. Those consequences are not consequences of badly designed or of otherwise flawed autonomous weapons - they are direct consequences of the mere idea of autonomous weapons. If a weapon is supposed to be actually autonomous, then it is unavoidable that it disrupts military chain of command and that it creates an enormous security risk. Therefore, the probability for this outcome is 1 .

\section{Conclusion: A strategic paradox}

Autonomous weapons are of interest to military forces around the world because such weapons might be able to achieve military goals more effectively and more efficiently than traditional weaponry. Autonomous weapons are a potentially enormously valuable strategic asset, and it is understandable why military forces are in the process of pursuing this asset. Implementing autonomous weapons might result in different outcomes with different probabilities. Those outcomes are summarized in Table 1 .

A highly probable positive outcome of implementing autonomous weapons are moral improvements on the battlefield. Unfortunately, the most probable outcome is highly undesirable: A disruption of the military chain of command. Such a disruption goes against an important military principle, and it creates a new source of security risks. The result is a strategic paradox for the military: Autonomous weapons might help the military achieve goals more effectively and efficiently, but they would also strategically undermine the military by disrupting the military chain of command and by creating great security risks. 
Table 1: Summary of plausible outcomes of implementing autonomous weapons.

\begin{tabular}{lll}
\hline Outcome & Desirability & Probability \\
\hline End of war. & best & $0.01-0.05$ \\
Moral improvements on the battlefield. & good & $0.8-1$ \\
Mutually assured AI destruction (MAAID). & OK & $0.05-0.15$ \\
Lowering the threshold for war. & bad & $0.1-0.2$ \\
Disrupting the military chain of command. & worst & 1 \\
\hline
\end{tabular}

\section{Policy recommendations}

Autonomous weapons would almost certainly result in a disruption of the military chain of command and the security risks that follow from that. Even though autonomous weapons could have significant positive impact in other contexts of military behavior and decision-making (most notably with regard to adherence to humanitarian law), the negative impact of autonomous weapons is both most probable and categorical. We therefore need appropriate policy responses to this problem.

\subsection{Military level: Abstaining from autonomous weapons}

Individual military forces should abstain from implementing autonomous weapons into their weaponry and into their strategy. Preventing military forces from doing so might be achieved by national policy that prohibits autonomous weapons. Explicitly codified policy, however, might not even be necessary: It is hard to imagine any military voluntarily disrupting their chain of command and thus voluntarily exposing itself to an enormous security risk. Military decision-makers, including higher ranking military personnel as well as elected politicians and appointed civilians in the legislative and executive branches, should be made aware of the negative consequences of autonomous weapons. Once the adverse implications of autonomous weapons become clear, so will the case against autonomous weapons.

\subsection{International level: Codification of an ordo belli}

Warfare is currently regulated, or at least evaluated, through the principles of jus ad bellum (rules for engaging in war) and jus ad bello (rules for behavior in war). In addition to those two principles, a third one seems in order. Something that might be referred to as ordo belli, the order of war. The goal of this new set of principles would be to make explicit the way in which a military force needs to 
operate in order to be considered legitimate. One guiding principle of the order of war should be the presence of a military chain of command.

The problem of the chain of command is not an entirely new one. For example, private military contractors are at least partly outside the military chain of command, even though they simply pursue goals given to them by their «clients», the military [21]. Codifying a set of principles that guide the order of war would therefore not only help with the regulation of autonomous weapons, but with other problems regarding the military chain of command as well. If one of the goals of an order of war is to preserve the military chain of command, then a likely outcome is that autonomous weapons will be banned for many military applications, and possibly altogether. 


\section{References}

[1] Steven Pinker. The Better Angels of Our Nature: Why Violence Has Declined. New York Toronto London: Penguin Books, 2012. ISBN: 978-0-14-312201-2 (cit. on p. 5).

[2] Joshua S. Goldstein. Winning the War on War: The Decline of Armed Conflict Worldwide. Penguin, 2011. ISBN: 978-1-101-54908-7 (cit. on p. 5).

[3] Thomas S. Szayna, Stephen Watts, Angela O’Mahony, Bryan Frederick, and Jennifer Kavanagh. What Are the Trends in Armed Conflicts, and What Do They Mean for U.S. Defense Policy? 2017 (cit. on p. 5).

[4] Armin Krishnan. Killer Robots: Legality and Ethicality of Autonomous Weapons. Ashgate Publishing, Ltd., 2009. IsBN: 978-0-7546-7726-0 (cit. on p. 5).

[5] Shane Reeves and William Johnson. Autonomous Weapons: Are You Sure These are Killer Robots? Can We Talk About It? SSRN Scholarly Paper ID 2427923. Rochester, NY: Social Science Research Network, 2014 (cit. on p. 5).

[6] Cassio Pennachin and Ben Goertzel. "Contemporary Approaches to Artificial General Intelligence”. In: Artificial General Intelligence. Cognitive Technologies. Springer, Berlin, Heidelberg, 2007, pp. 1-30. ISBN: 978-3-54023733-4 (cit. on p. 6).

[7] Vincent C. Müller and Nick Bostrom. "Future Progress in Artificial Intelligence: A Survey of Expert Opinion”. In: Fundamental Issues of Artificial Intelligence. Synthese Library. Springer, Cham, 2016, pp. 555-572. ISBN: 978-3-319-26483-7 (cit. on p. 6).

[8] Carl von Clausewitz. On War. Jazzybee Verlag, 1940. ISBN: 978-3-8496-76056 (cit. on p.7).

[9] “Charter of the United Nations”. In: American Bar Association fournal 31 (1945), p. 388 (cit. on p. 7).

[10] Hans Kelsen. "Collective Security and Collective Self-Defense Under the Charter of the United Nations". In: American fournal of International Law 42.4 (1948), pp. 783-796. Dor: 10 . 2307 / 2193350 (cit. on p. 7).

[11] "The growing danger of great-power conflict". In: The Economist (2018) (cit. on p.7).

[12] Dave Grossman. On Killing: The Psychological Cost of Learning to Kill in War and Society. Open Road Media, 2014. ISBN: 978-1-4976-2920-2 (cit. on p.77. 
[13] Jean-Marie Henckaerts and Louise Doswald-Beck. Customary International Humanitarian Law. Cambridge University Press, 2005. ISBN: 978-0-52180899-6 (cit. on p. 8).

[14] Gregory P. Noone and Diana C. Noone. "The Debate over Autonomous Weapons Systems". In: Case Western Reserve fournal of International Law 47 (2015), p. 25 (cit. on p. 8).

[15] Marco Sassoli. "Autonomous Weapons and International Humanitarian Law: Advantages, Open Technical Questions and Legal Issues to be Clarified". In: International Law Studies / Naval War College 90 (2014), pp. 308340 (cit. on p. 8).

[16] Ronald C. Arkin, Patrick Ulam, and Brittany Duncan. An Ethical Governor for Constraining Lethal Action in an Autonomous System. Tech. rep. GITGVU-09-02. GEORGIA INST OF TECH ATLANTA MOBILE ROBOT LAB, GEORGIA INST OF TECH ATLANTA MOBILE ROBOT LAB, 2009 (cit. on p. 8).

[17] Henry D. Sokolski. Getting MAD: A nuclear mutual assured destruction, its origins and practice. Carlisle, Pa.: University of Michigan Library, 2004. ISBN: 978-1-58487-172-9 (cit. on p.9).

[18] Philip Zelikow. Essence of Decision: Explaining the Cuban Missile Crisis. Longman, 1999. ISBN: 978-0-321-01349-1 (cit. on p.9).

[19] Heather M. Roff. "The Strategic Robot Problem: Lethal Autonomous Weapons in War”. In: Journal of Military Ethics 13.3 (2014), pp. 211-227. Dor: 10 . 1 080/15027570.2014.975010 (cit. on p. 11).

[20] "For artificial intelligence to thrive, it must explain itself". In: The Economist (2018) (cit. on p. 11).

[21] Peter W. Singer. Can't Win with 'Em, Can't Go To War without 'Em: Private Military Contractors and Counterinsurgency. Policy Paper 4. Washington, D.C.: Brookings, 2007 (cit. on p. 14). 